\title{
DisPUTAS SOCIOLÓGICAS \\ E SEUS RECURSOS INTELECTUAIS
}

\author{
BRUNO NOGUEIRA
}

\begin{abstract}
This essay aims to picture pieces of contemporary sociological debates, concerning epistemological issues. A dichotomy between term and concept will be developed to clarify the ideas that will relate a celebrated author - Pierre Bourdieu - with two more recent names - John Law and Bruno Latour - that presented new long range theories, in which one can immerse to account a very unorthodox sociology. In the source of this dichotomy there is a modernist epistemology that will be roughly (re)elaborated before the account of the other subjects. It will be suggested that the non-observation of some epistemological details follows some critiques in the debates, as well as the debate itself, fueling the plausibility of the concerning authors' sociological theories.
\end{abstract}

Keywords: Epistemology of critique; critical relativism; Kantianism; modernism.

O sujeito está interpolado em uma dessublimação cultural que inclui a cultura como uma realidade. Em certo sentido, se o paradigma patriarcal de expressão se mantém, temos que escolher entre o construtivismo e a teoria neomaterialista.

- Gerador pós-moderno ${ }^{1}$

\section{Introdução}

Nos programas curriculares de cursos de teoria sociológica contemporânea, é frequente encontrar disputas intelectuais entre diferentes sociólogos/filósofos, em que embates conceituais são desenvolvidos pela criação de novos sentidos para palavras, e assim há o que pode ser chamado de teorização: um conjunto de sentenças articulado por um "conjunto de sentidos", especialmente encrustados no contexto semântico maior (o paradigma/regras tácitas).

Um dos pontos de sustentação dessa produção teórica múltipla se encontra na relativa liberdade intelectual acadêmica e no princípio do antidogmatismo: pensa-se a produção intelectual como etapas de um processo cujo fim não está determinadoque muitos diriam ser indeterminável. Partindo dessa premissa, o diálogo entre autores é visto como uma construção não linear de polos de conhecimento semi-independentes, no caso de diálogos teóricos sem corolários básicos consensuais, como é comum em sociologia e filosofia e será mostrado adiante.

Principia 18(3): 371-391 (2014).

Published by NEL — Epistemology and Logic Research Group, Federal University of Santa Catarina (UFSC), Brazil. 
Esse ensaio tentará mostrar alguns métodos de crítica decorrentes da ausência de uma teoria unificada em sociologia, no caso de três autores-alvo: Pierre Bourdieu, Bruno Latour e John Law. Será argumentado que suas críticas a outras teorias usam como critérios suas próprias formulações conceituais - não compartilhadas com as vítimas da crítica - sem denotar que a natureza desse tipo de crítica impede de caracterizá-la como uma refutação apropriada dos argumentos-alvo.

As obras em questão dos três autores analisados são teóricas de longo alcance: suas proposições não possuem uma delimitação clara do campo empírico em que possam estar restritas. Suas críticas são (parcialmente) motivadas pelo interesse em justificar a aplicação das próprias teorias, como se estas fossem uma "melhor apreensão do que se deveria apreender".

Tentar-se-á resgatar o relativismo filosófico para desmistificar essa ideia e mostrar que o que está em jogo são concepções particulares, cada qual com grupos que a adotam por preferência pessoal ou algo do gênero, devido à grande liberdade do campo sociológico, que não possui muitas regras para a incursão teórica, quando comparado com outras disciplinas científicas. Essa ausência de regras pode subsidiar racionalidades bastante alternativas quando comparadas ao "pensamento moderno tradicional".

Na primeira parte, será elaborada uma pequena "epistemologia modernista", com o objetivo de fundamentar o relativismo que será utilizado contra as críticas de tais autores. Em seguida, será tecida uma distinção entre termo e conceito, calcada na epistemologia modernista, e mostrar-se-á que a confusão entre os dois provoca disputas infrutíferas, mas que representam a multiplicidade semântica e o politeísmo de valores — várias visões de mundo em um combate interminável.

Essas confusões estão presentes nas produções teóricas dos autores analisados. Bourdieu será posto em perspectiva na sua crítica a Levi-Strauss e ao "objetivismo" e seguirá uma "crítica da crítica" sob as lentes modernistas. Contudo, o lado de Bourdieu modernista também será mostrado, ao se denotar sua epistemologia da produção sociológica. Em seguida, o mesmo procedimento será adotado para Law e Latour. Seus trabalhos podem ser considerados uma crítica às próprias lentes modernistas, que serão usadas para avaliá-los. Isto em certa medida encaixa no dito acima infrutífero, contudo não se deseja com isso tentar refutar as teorizações de tais autores pois isto seria cair na armadilha a ser evitada - mas esclarecer o cenário do debate teórico.

\section{Epistemologia modernista}

Tento formular aqui um tipo de pensamento neo-kantiano, a ser utilizado como ilustração de uma epistemologia moderna largamente compartilhada, ${ }^{2}$ sugerida aqui

Principia 18(3): 371-391 (2014). 
como base para a construção de conhecimento científico, e para a compreensão da verdade em sua relação com humanidade e natureza. Segundo essa tradição de pensamento, o conhecimento do mundo externo é fruto de uma relação entre sensação e razão, ancorada por faculdades cognitivas propriamente humanas. Frisa-se com isso que há uma diferença entre o fenômeno e o númeno, sendo acessível a nós apenas o primeiro. O segundo, que pode ser entendido como a realidade plena das coisas, está fora da órbita da ciência e do conhecimento moderno. ${ }^{3}$ Ademais, a distinção entre sujeito e objeto é característica dessa racionalidade, bem como a não hierarquização de forças mentais contra materiais, atentando-se com isso que na realidade as duas existem em um processo único.

Com isso a metafísica tradicional é excluída do conhecimento razoável, por se tratar de tentativa de apreensões de totalidades de conceitos. Estes, como a "Natureza", são a imaginação de entidades, e sua construção intelectual pode conduzir em última instância ao dogmatismo ou a experiências místicas. Talvez a entidade nodal para a epistemologia modernista seja a Natureza, no sentido de que é uma premissa para as ciências modernas a existência de um mundo externo que pode ser organizado em um conhecimento sistemático que apreende algum aspecto de sua lógica.

Nessa tradição, é inconcebível separar o conhecimento do conhecedor, ${ }^{4}$ pois o primeiro sempre está circunscrito a critérios sociais e culturais. ${ }^{5}$ Kant postulava critérios humanos gerais (o sujeito transcendental é uma abstração universalista), mas seus seguidores nas ciências sociais, como Weber e Simmel, fizeram a guinada cultural para a aqui chamada epistemologia moderna. Estes sociólogos, suavizando o velho Kant, relativizaram as pretensões epistemológicas do positivismo, que via o conhecimento científico como inexorável. Com isso a síntese kantiana da empiria com a razão, que antecipa todo o conhecimento humano, foi mantida, e a objetividade legitimada mesmo em face aos novos limites encontrados.

Seguindo essa linha, o conhecedor também não pode ser separado de sua comunidade, que tem a autoridade (sociocultural) para avaliar e legitimar os diversos conhecimentos, imputando o que é o caso ou não. A Academia é um ótimo exemplo, visto que na maioria das vezes a produção acadêmica é qualificada e transmitida por pares. Essa natureza comunitária do conhecimento remete à impossível separação apontada acima, entre conhecimento e conhecedor, e entre homem e natureza. Tais condições epistemológicas também podem ser bem entendidas seguindo os termos de Bourdieu como habitus e campo (1989, p.28-29, p.59-73), que denotam espaços sociais que possuem uma lógica interna, fundada na relação dinâmica entre estrutura e agência que existe através das práticas.

Em suma, o conhecimento é restrito, circunscrito e comunitário. Restrito a recortes da realidade, visto que a totalidade é inapreensível; circunscrito à cultura, que condiciona os possíveis métodos para tratar dos recortes; e comunitário, pelas impulsões que valorizam certos caminhos em detrimento de outros. Os objetos do 
conhecimento são fruto de afinidades eletivas, ou seja, são seleções "arbitrárias", 6 o que não tem implicações necessárias sobre o não selecionado. Após tal seleção, critérios de lógica e empirismo são invocados, para caracterizar o conhecimento como objetivo. Dessa forma, racionalismo e empirismo se coordenam, e a possibilidade de existência do conhecimento é explicada.

\section{Conceitos e termos}

Dentro do paradigma modernista acima exposto, a pergunta "o que é sociologia?" pode ser encarada de duas formas: 1) como conceitual, e dessa forma carece de uma resposta amplamente satisfatória, já que conceitos são inapreensíveis em sua totalidade; 2) como terminológica, aplicando-se um método que corrobora os quesitos acima expostos, ou seja, designa-se uma parte do conceito, e pode-se denotar, por exemplo, que ela é uma disciplina entre várias outras, grosso modo o objeto de interesse dos sociólogos. Uma intelecção terminológica jamais esgota as possibilidades semânticas de uma palavra.

Uma das maiores confusões que pode haver intelectualmente é a mistura do termo com o conceito. O uso que é feito da teoria da relatividade, por exemplo, em certos livros de autoajuda, reflete os efeitos de se empregar um conceito (energia e matéria) e subsidiá-lo com usos completamente distintos, desatentando seu caráter terminológico na física, em que devem ser entendidos sob uma linguagem particular. Essa mistura já resultou em uma grande polêmica, chamada "Guerras da Ciência", quando o físico Alan Sokal publicou um texto (1996b) utilizando termos da física no que ele mais tarde considerou uma forma inapropriada (1996a). O que está em jogo aí é uma disputa por quais usos das palavras são legítimos e quais não são. Sokal parece ser contra a utilização dos termos enquanto conceitos, enquanto seus adversários - os "pós-modernos" - são partidários da força conceitual das palavras, por onde os benefícios intelectuais da criação semântica são tão ou mais importantes do que uma restrição designográfica.

Primar pelo conceito, em detrimento do termo, se estendeu para além da filosofia, campo que tem um menor "compromisso empírico" em relação a outras disciplinas acadêmicas. Podemos ver seus efeitos em diversos sociólogos, como Foucault e mais recentemente Latour, como será comentado adiante. Isso resulta no que Luís Gusmão chama de fetichismo do conceito (2012), quando as preocupações com palavras se tornam mais importantes do que o objeto de pesquisa. Descendentes do idealismo de Hegel, os "palavristas" muitas vezes enxergam conexões metafísicas que vão além da razoabilidade modernista. Tais visões do além-mundo estão bastante presentes em debates sociológicos contemporâneos, e fundamentam diversas críticas.

As premissas que fundamentam essa distinção estão presentes em uma miríade

Principia 18(3): 371-391 (2014). 
de pensadores modernos, sendo que traçar fronteiras claras de suas fontes não é possível em um curto ensaio. Exemplos das influências estão no método pragmático de William James: "tentar interpretar cada noção traçando as suas consequências práticas respectivas" (1979a, p.18), o provérbio latino Quod gratis asseritur, gratis negatur (também conhecido como Navalha de Hitchens - o que pode ser assumido sem evidência pode ser refutado da mesma forma) e a navalha de Occam (e os efeitos na filosofia analítica, cf. Haddock 2013, p.235-6). Contudo, mais fundamentais são as ideias modernistas acima expostas, e as distinções entre sujeito e objeto, linguagem e realidade externa, e conceituações semelhantes empregadas na esteira de Kant. Há certamente uma posição antimetafísica, resultado da busca por horizontalizar experiências - "as relações que ligam experiências devem elas mesmas ser relações experienciadas, e qualquer espécie de relação experienciada deve ser considerada tão 'real' quanto qualquer outra coisa no sistema" (James 1979b, p.188); e expressões — "Todas as proposições têm igual valor." (Wittgenstein 1968, p.126). O resultado antimetafísico, no entanto, caracteriza-se em um deflacionismo que visa equilibrar os enunciados com seus contextos, em um constante ato de se jogar fora a escada (ibidem, p.129).

A conclusão que segue, tendo em mente o relativismo crítico em questão, é que não há a priori um conjunto de ferramentas teóricas mais adequado ao objeto de pesquisa. O caso é de grupos de sociólogos com linguagens distintas para abordar seus objetos. Também não ocorre consenso sobre quais são os objetos. O que advém com frequência é que as críticas a outros sociólogos usam como base um objeto que não era o deles, e nem uma linguagem. A noção de termo é ignorada nessa empreitada: as limitações contextuais dão lugar para os limites conceituais.

\section{Pierre Bourdieu em perspectiva}

Vemos a confusão entre termo e conceito adquirir dimensões titânicas, uma vez que está presente em sociólogos notórios aos alunos dos cursos de sociologia. Bourdieu é um dos sociólogos mais citados das últimas décadas, e direcionou críticas ao estruturalismo, Lévi- Strauss, e ao que chamou de "juridismo" ou "objetivismo" (2003, p.56-60, grifo nosso):

o objetivismo está condenado ou a deixar na mesma a questão do princípio de produção das regularidades que ele se contenta então em registrar, ou a reificar abstrações, por um paralogismo que consiste em tratar os objetos construídos pela ciência [...] como realidades autônomas [...] [2] Todas as proposições do discurso sociológico deveriam ser precedidas por um signo que se leria "tudo se passa como se..." e que, funcionando à maneira de quantificadores da lógica, lembraria continuamente o estatuto epistemológico dos conceitos construídos da ciência objetiva.

Principia 18(3): 371-391 (2014). 
As críticas de Bourdieu ao objetivismo ficam menos relevantes ao pensarmos nos objetos da crítica como empregadores de termos, e não conceitos. Isso significa que modelos teóricos somente são avaliáveis dentro das expectativas que eles constroem de si mesmos e não pelas possibilidades semânticas, pelos "mundos possíveis", que podem ser conscientemente elaborados pelos críticos utilizando palavras em elaborações conceituais multiformes. Reificar abstrações está mais relacionado com a metafísica, ${ }^{7}$ que concede o primado ao conceito em detrimento de questões práticas, do que com a ciência, voltada aos usos terminológicos, heurísticos, sendo que numa linguagem científica (lógica) ideal cada objeto tem um nome (signo linguístico) próprio (cf. Wittgenstein 1968). Dificilmente uma crítica à ciência desse tipo pode ser sustentada sem inflar os argumentos-alvo.

Bourdieu afirma que o objetivismo estaria condenado, mas, sob a ótica da epistemologia modernista, os contrapontos apontados para desqualificar tais construções intelectuais, como as de Saussure ou Lévi-Strauss, são de ordem subjetiva, isto é, dizem mais sobre o conceito bourdieusiano (e de seu Zeitgeist intelectual) de sociologia. Para validar seu conceito, sugere-se que ele é mais "completo". No debate sociológico contemporâneo, a questão da completude impinge as querelas intelectuais com força tremenda. Quer-se dizer com isso que diversas críticas são fundamentadas no sentido de um "não foram vistos todos os aspectos relevantes do objeto", ignorandose assim a ausência de método para estipular seu tamanho adequado. Com isso não desejo clamar por um silêncio quando as críticas vão para esse âmbito subjetivofilosófico, apenas ressaltar que dessa maneira não se está refutando pretensões de conhecimento, mas apontando para a irrelevância destes em face de novas expectativas intelectuais. Bourdieu não está desqualificando os argumentos por serem falsos, ao invés disso ele aponta para seu próprio "discurso do método", que em sua visão se encaixa melhor com os objetivos da sociologia e da antropologia. ${ }^{8}$

Sobre a segunda passagem, ela é um tanto tautológica ao se ter em mente a distinção entre fenômeno e númeno, e que apenas o primeiro é abordável cientificamente. Pretensões de codificar (representar via linguagem) a totalidade de um objeto, segundo o postulado moderno, são inviáveis. Isso acaba com pretensões positivistas - como a de Durkheim, que pensava que a sociologia alcançaria um dia a essência última da realidade social (1978) — de alcançar uma perfeição de conteúdo, uma verdade absoluta. Contudo, não acaba com a possibilidade de "microverdades", viabilizada pelos quesitos acima expostos, mesmo com os "vieses tácitos" da inserção em campos e habitus específicos. Isso significa que sempre haverá algum tipo de postulado/premissa em qualquer ciência (no limite, há os axiomas linguísticos, cf. Pears 1973).

Bourdieu em sua prática sociológica corroborou a possibilidade de uma "verdade relativa", cristalizada pelos critérios socioculturais, e tentou encontrar um meio termo científico entre as abstrações do conhecimento e os agentes que os pensam. "Bourdieu 
criticou fortemente o que chamou de 'teoria teórica' - isto é, trabalhos que estão mais preocupados em construir sistemas abstratos de categorias e conceitos do que em usá-los para entender o mundo" (Calhoun et al., 2012, p.325; cf. Swartz 1997, p.1-14). Nesse sentido, sua posição epistemológica é bastante convergente com a aqui nomeada tradição modernista (Bourdieu 2011, p.86):

O ultrarradicalismo de uma denúncia sacrílega sobre o caráter sagrado da ciência, que tende a lançar suspeita sobre todas as tentativas de fundar, ainda que sociologicamente, a validade universal da razão científica, leva naturalmente a uma espécie de niilismo subjetivista: assim é que o princípio de radicalização que inspira Steve Woolgar e Bruno Latour os leva a forçar até o limite ou reduzir ao absurdo análises que, como aquelas que propus há mais de dez anos, esforçam-se por escapar à alternativa entre o relativismo e o absolutismo. Lembrar a dimensão social das estratégias científicas não é reduzir as demonstrações científicas a simples exibicionismos retóricos; invocar o papel do capital simbólico como arma e alvo de lutas científicas não é transformar a busca do ganho simbólico na finalidade ou na razão de ser únicas das condutas científicas; expor a lógica agonística de funcionamento do campo científico não é ignorar que a concorrência não exclui a complementaridade ou a cooperação e que, sob certas condições, da concorrência e da competição é que podem surgir os "controles" e os "interesses de conhecimento" que a visão ingênua registra sem se perguntar pelas condições sociais de sua gênese.

Vemos aqui uma relação epistemológica de Bourdieu com o pós-positivismo, sendo seu método de observação participante uma "tradução criativa dos princípios pós-positivistas do método científico da esfera das ciências naturais ao domínio das ciências sociais" (Jain 2013, p.112, tradução nossa), por fornecer uma alternativa entre o realismo e o racionalismo, explicando assim a possibilidade de objetividade em condições socioculturais subjetivas. A manifesta preocupação bourdieusiana em elucidar tais condições socioculturais, refletindo sobre suas influências na construção do objeto de pesquisa, pode ser associada à ausência de uma teoria unificada em sociologia. Em outras ciências, postulados agem com mais intensidade para determinar regras de conduta e para limitar a influência da subjetividade nas construções intelectuais. A sociologia, no entanto, pode ter a construção social desses postulados como objeto de pesquisa, em um processo que não tem postulados consensuais, imputando perenes considerações reflexivas entre sociólogos, bem como disputas entre versões de análise: "sociólogos devem considerar em sua pesquisa o fato de que suas construções são construções de construções, as quais, ademais, são em si enredadas nas disputas entre visões concorrentes para estabelecer a verdade do mundo social" (ibidem p.105, tradução nossa). Assim, a dimensão social da construção do conhecimento, objeto de interesse sociológico, possui a característica da reflexividade, uma vez que a pesquisa sobre o assunto é ela própria um possível objeto de outra pes- 
quisa - e até dela mesma, exemplificado em trabalhos como o de Bourdieu sobre a educação francesa (Bourdieu; Passeron 2008) — havendo desta maneira uma maior elasticidade de abordagens sobre os objetos.

De fato, como encarar a reflexividade durante a prática sociológica é mais um caso de dissenso entre sociólogos. Bourdieu a encarou como uma acompanhante necessária para as ciências sociais. No entanto, há aqueles que encaram a metateoria como um beco sem saída, ou que a tomam como mais um campo de pesquisa entre vários outros (Swartz 1997, p.10-12). Tendo isso em mente, é possível levantar questões interessantes: este ensaio pode ser entendido como uma metateoria da sociologia. No entanto ele é necessário para esta? Em que grau? Ele próprio seria sociologia? Os limites entre uma incursão filosófica e outra sociológica também são bastante turvos. Ademais, é possível encarar a reflexividade como um ressalto dos princípios epistemológicos modernistas acima expostos: o pesquisador está condicionado pelo que lhe foi oferecido em vida, circunscrito por determinadas ferramentas de pesquisa. Tentar separar as ideias individuais do condicionamento social que as possibilita pode ser entendido como um dogma do empirismo (Davidson 1973-1974), mas que faz parte da heurística científica.

\section{John Law e a busca da completude}

Enquanto Bourdieu propõe uma compatibilização entre as pretensões de verdade da ciência e a contingência social que é de importância sociológica, John Law sugere um programa de pesquisa social que encara os objetivos a serem perseguidos de forma bastante heterodoxa (2004, p.9-10, tradução nossa):

Meu objetivo é então ampliar o método, subvertê-lo, mas também recriá-lo. Eu gostaria de despir a preocupação com método de sua herança da higiene. Desejo me mover da ideia moralista de que somente se você faz seus métodos propriamente você levará uma vida de pesquisa saudável — a ideia de que você irá descobrir verdades específicas sobre as quais todas as pessoas razoáveis podem ao menos temporariamente concordar. [...]

Método? Com o que estamos lidando aqui não é, claro, apenas método. Não é apenas um conjunto de técnicas. Não é apenas uma filosofia do método, uma metodologia. Nem é simplesmente sobre os tipos de realidades que desejamos reconhecer ou os tipos de mundos que podemos esperar criar. É também, e mais fundamentalmente, sobre um modo de ser.

A necessidade de revolução metodológica é motivada pela crença em um mundo essencialmente não-coerente, menosprezado pelo "senso comum realista euramericano", termo utilizado nos artigos de seu site. ${ }^{9}$ Segundo Law, a ortodoxia das ciências sociais sempre considerou o mundo "um conjunto de processos possivelmente 
descobríveis" (ibidem p.9). No âmbito modernista acima traçado, é bem irrazoável argumentar que o mundo da ciência (qualquer uma) equivale ao mundo total. Primeiro porque o conhecimento científico é melhor compreendido como um processo de construção intelectual disposto a se atualizar frente a novos argumentos, ou seja, não é um sistema intelectual encerrado. Segundo que tal proposição é de caráter ontológico, que cientificamente não faz o menor sentido. E finalmente, há a questão lógica: pensar que "o mundo é um caldo performativo de efeitos não coerentes, e por isso a ciência social também demanda métodos não coerentes" é algo coerente? Abandonando a lógica, resta recorrer à ética: como bem colocado por Law, sua proposta é sobre um modo de ser, um apelo aos desinteressados pelo tédio da pesquisa tradicional. ${ }^{10}$

Não obstante, o escopo teórico não é para deslegitimar métodos científicos. O objetivo é acrescentar-lhes aqueles não científicos (e até ilógicos), com a crença de que estes são imprescindíveis no conhecimento do mundo externo. Em algum nível é possível identificar a presença de alguns postulados consonantes com a epistemologia modernista: o mundo é complexo, com conteúdos a serem descobertos pela investigação, e as metodologias usadas nessa tarefa são seletivas de conteúdos, deixando necessariamente outras coisas de lado. As características do conhecimento sugeridas acima (restrição, circunscrição e comunhão) podem ser identificadas na proposta de Law.

No entanto, tal identificação pode ser considerada bastante forçada ao se analisar as conclusões tomadas, que motivaram o livro de Law. Intelectuais pós-positivistas, como Bourdieu, corroboraram com a ideia de verdade como aproximação e não viram aí uma dissolução da metodologia e racionalidade científica: ao mirar a complexidade do mundo, concluíram que por isso mesmo devemos ter especial cuidado com as proposições e sua correspondência com os objetos - a investigação sociológica nunca levaria a uma exaustão plena do objeto, que permaneceria com aspectos inefáveis ou obscurecidos pelas restrições socioculturais do pesquisador e/ou sua comunidade. $\mathrm{O}$ pesquisador deve estar ciente das restrições impostas ao seu conhecimento, por força de tais circunstâncias. Ademais, a contingência social não significaria um anarquismo epistemológico, mas apenas que a razoabilidade coletiva que legitima as regras está circunstanciada por fatores em última instância ininteligíveis - não é possível sair do conjunto de experiências pessoais e linguagem em que estamos inseridos para um detalhamento claro de suas fronteiras: "Até aqueles pensadores que estão certos de que há apenas um esquema conceitual estão subjugados ao esquema conceito; até monoteístas têm religião." (Davidson 1973-1974, p.5, tradução nossa)

O que pode ser visto em Law é um caminho ao polo oposto das conclusões científicas que podem surgir desse contexto epistemológico. Em vez de cuidado, o desenlace é pela balbúrdia (2004, p.155-156, tradução nossa, grifo no original): 


\begin{abstract}
Não há mundo geral e não há regras gerais. [...] O geral, então, desaparece, junto ao universal. A ideia da transportabilidade universal do conhecimento universal foi sempre uma quimera. [...] Em longo prazo não é mais óbvio que as disciplinas e campos de pesquisa da ciência e ciências sociais são apropriados em sua forma presente. Não é mais óbvio que uma divisão do trabalho é desejável, uma divisão do trabalho fundada sobre o parcelamento de partes de verdade para diferentes especialistas que então são despidos da necessidade de praticar outros bens.
\end{abstract}

Segue-se uma desconstrução do paradigma científico básico, de busca da verdade e consistência lógica e empírica. O conceito de mundo é invocado para corresponder ao conceito de método de Law: qualquer coisa que expresse algo significativo. E para quem? A questão fica suspensa: o teórico não aborda o problema da razoabilidade de forma a explicar porque suas opiniões deveriam ser aceitas pela comunidade sociológica. Ademais, seu conceito de universal parece estar mais associado a Platão que à ciência moderna: uma entidade existente alheia às práticas (o que justifica a crítica). Em ciência, a ideia está associada à pretensão de objetividade, à expectativa de que o conteúdo de conhecimento não seja refém da opinião (fugir da individualidade, como diz Bachelard), portanto sendo um princípio, e não uma afirmação factual.

Outra fonte de sua ideia de universal vem dos chamados Estudos de Ciência e Tecnologia (ETS). O escopo da escola é tratar a ciência de forma externa: "trata-se de fazer o que fazem todos os etnógrafos, e de aplicar à ciência a deontologia habitual às ciências humanas: familiariza-se com um campo, permanecendo independente dele e à distância" (Latour; Woolgar 1997, p.26). O que os próprios cientistas pensam é tratado em segundo plano, para priorizar as considerações do observador. Dentro desse ambiente intelectual, na qual as verdades científicas são abordadas enquanto discurso, subjetivas ao cientista e a quem por ele se convence, é até compreensível que surjam críticas ao termo universal. Mas o que Law não deixa claro são as diferenças conceituais, as distinções do termo, e a limitação de sua proposta a uma concepção de ciência restrita. Assim confusões não poderiam deixar de ocorrer.

Assim como Latour (2005), Law se enxerga como cabeça de um movimento intelectual a trazer renovação para as ciências sociais, para atender a expectativas intelectuais no métier da disciplina. Contudo, ambos os autores minimizam a questão da razoabilidade de suas propostas, principalmente no diálogo com a aqui chamada epistemologia modernista. Talvez seja mesmo apenas o caso de aceitar que são visões de mundo diferentes, com regras distintas para fundamentar linhas de raciocínio, e que disputas intelectuais seriam infrutíferas. Como Law afirma, é uma proposta por um modo de ser, uma normatividade. Um método de pesquisa sociológica, originado na sociologia da ciência que se tornou os ETS, adquire uma grande inflação de escopo no advento das teorias de John Law e Latour: um recorte da realidade desejando ser a realidade total.

Principia 18(3): 371-391 (2014). 
Ao sentir uma exigência de completude para a pesquisa social corresponder adequadamente ao que lhe interessa, Law entende que vários métodos são admissíveis, e vários "bens" podem ser o padrão de qualidade, e não somente a verdade. Política, justiça, estética, inspiração e espiritualidade podem ser critérios (2004, p.149-51). Os impactos decorrentes são demasiado complexos para serem esmiuçados, mas gostaria de ressaltar dois pontos: 1) pelo seu conceito de pesquisa social, a obra Cidade de Deus, de Santo Agostinho, poderia ser considerada sociologia; 2) a questão das "razoabilidades comunitárias" - em particular as normas acadêmicas de aceitação de produção de conhecimento - não é abordada. São dois pontos-chave uma vez que uma miríade de sociólogos discordaria de 1 , e vários também questionariam a adequação de tal programa aos objetivos da sociologia acadêmica.

Law parece sugerir que a sociologia é uma coleção de expressões, um amontoado de "sobreposições específicas e atuadas entre realidades provisoriamente congeladas" (ibidem, p.155, tradução nossa). Se há um pano de fundo moderno, sobre a relação do conhecimento com o mundo, isso não apenas desmistifica o conhecimento como um espelho da ontologia da natureza, como faz Bourdieu. Na era "pós-método" significa um novo conceito de conhecimento: a mistura de conceitos e termos se torna tão grande que é irrelevante tomá-la como um problema. Em Law ela é uma virtude.

Não creio ser possível fazer uma boa crítica da posição de Law: como posto acima, conceitos são polissêmicos, cada pessoa pode entender palavras da maneira que quiser, e escrever livros para manifestar suas visões de mundo. Criticar aqui seria algo do tipo: "meu conceito é melhor que o seu", e não há regras para progredir com essa discussão. Mas para a vida acadêmica, põem-se questões de grande relevância: se não há mais método, como que se distingue uma boa pesquisa de uma ruim? $\mathrm{E}$ se a verdade não é o único "bem", é aceitável mentir com o fim de acentuar outros bens? O pós-método parece implicar que basta adequação gramatical ou então buscar as autoridades certas, que possuam os mesmos critérios pessoais de qualidade. A epígrafe deste ensaio seria válida, por trazer um "bem de inspiração".

O que é talvez irônico é o próprio estilo utilizado por Law durante o livro: claro, coeso e coerente na maior parte do tempo. O novo linguajar que ele deseja implantar não é utilizado: seu estilo é bastante lógico. O mesmo vale, por exemplo, para um artigo escrito por ele em pesquisa social (Ruper, Law, Savage 2013), onde não há muito distanciamento da linguagem científica padrão (clara, coesa e coerente), e os postulados teóricos de After Method estão presentes em um grau amistoso àqueles que discordam deles: podem ser entendidos como recursos estilísticos, que não prejudicam a ilustração das ideias retiradas da pesquisa.

Pode-se argumentar que a proposta do pós-método produz uma visão de mundo (uma ontologia) capaz de programar todos os princípios de pesquisa de um sociólogo, bem como sua interpretação dos fenômenos. E de fato, muitos tomam para si tais manifestações conceituais. No entanto, a mistura entre termo e conceito pro- 
duz querelas intelectuais que não ajudam ninguém. Sokal e seus adversários nunca irão chegar a uma síntese ideológica, pois cada lado adota paradigmas incomensuráveis. Em sociologia, estar ciente dessa distinção contribuirá para o pensamento independente, e não se perderá de vista que cada autor não produz realidades, mas interpretações. ${ }^{11}$

\section{O mundo mágico de Bruno Latour}

Em bastante proximidade com John Law está Bruno Latour, outro avatar do debate sociológico contemporâneo. Ambas as propostas teóricas, de longo alcance, podem ser descritas como tentativas "de entender, descrever e explicar o social por meios não tradicionais" (Czarniawska 2005, p.1553). E a reviravolta conceitual latourniana é radicalmente antitradicional, por ir a uma direção muito oposta das premissas epistemológicas modernas. A síntese neo-kantiana que situa o conhecimento em seu contexto é ignorada (Vandenberghe 2006, p.318):

Quando Bourdieu tentou integrar as três variantes do construtivismo social em uma teoria neo-kantiana do conhecimento sociológico que rompe, em um primeiro momento, com a constituição do mundo ordinário pelo senso comum para, em um segundo momento, reintegrá-lo, dialeticamente, em uma fenomenologia crítica da constituição dóxica do mundo, Latour desfez a síntese bourdieuniana, radicalizando e pós-modernizando o construtivismo constitutivo dos etnometodólogos

As influências da etnometodologia em Latour pós-modernizaram seu pensamento por querer transformar um método na essência da realidade (assim como o fez Law). Garfinkel (1967) enquadrou o programa etnometodológico como uma "tradução" de processos empíricos de gênese de significados, das expressões contextuais e práticas dos agentes para uma linguagem sociológica. Com um dialeto particular, Latour almeja transplantar o construtivismo constitutivo da etnometodologia para uma ambiciosa ontologia. Do início de sua trajetória acadêmica, com um foco de pesquisa específico (fazer uma etnologia de laboratório, 1997 [1979]), o projeto foi se expandindo, ganhando grandes proporções em Jamais Fomos Modernos (1994), e Reassembling the Social (2005). Unindo essas três obras, está a radicalização de um método, uma miríade de conceitos exóticos (híbridos, quaseobjetos, associações, etc.) e uma prosa autocentrada. No cerne de sua epistemologia, busca-se dissolver distinções modernas, que tornariam seus partidários "prisioneiros de uma dicotomia absoluta entre coisas e signos, fatos e valores" (2012, p.548, tradução nossa). As consequências desse esquema são bastante curiosas: com frequência o leitor se encontra imerso no conceituário particular de Latour, incapaz de esclarecer se algo é uma convicção pessoal do autor, ou uma proposição de ambição objetiva, i.e. que planeja se referir a

Principia 18(3): 371-391 (2014). 
um estado de coisas independente da linguagem. A mistura de termos e conceitos, então, ganha dimensão conspícua: boa parte dos primeiros, como "modernos", "prémodernos" e "pós-modernos" parecem habitar a atmosfera mental do autor, sem ficar claro ao que estão se referindo (pessoas, ideais, sociedades?). Pós-modernizar, como diz Vandenberghe, parece justamente esse turbilhão linguístico em que se encontra Latour em diversos momentos de sua obra, em que as fronteiras entre o fictício e o real estão fora de questão. Os poucos diálogos com uma tradição de pensamento modernista não parecem levar a conclusões (Latour 1997, p.30)

Mas o que pode fazer um sociólogo das ciências que busca a simetria e que se esforça por explicar com os mesmos termos o erro e a verdade, a natureza e a sociedade? Ele priva-se de duas das mais fortes pragas: a distinção entre o verdadeiro e o falso e a distinção entre a natureza e a cultura. Se desconstruímos as ciências exatas, que crédito deve ser concedido à nossa desconstrução? [...] Ao privar-nos da distinção entre verdadeiro e falso, entre natureza e cultura, nós nos privamos, do direito de estabelecer uma metalinguagem mais forte que a das ciências.

Como consequência de noções como esta Latour se legitima a criar sua própria linguagem, que servirá de base para as obras teóricas referidas. Termos como híbridos, redes, associações, inter alia ganham conotação endêmica, dos quais um leigo poderá não absorver coisas - apenas nomes. E até mesmo um não leigo se encontrará perdido, ao se preocupar com a distinção significante/significado, por exemplo. ${ }^{12}$ Afinal, o que são híbridos? Onde estão os modernistas que Latour conceitua, mas que não parecem ser nem pessoas, nem ideologias? Estariam em algum lugar, além do discurso latourniano? Latour parece ser partidário de um monismo ontológico, ${ }^{13}$ que, ao advogar pela desconsideração de distinções entre natureza e cultura, fatos e valores, coloca no mesmo plano as articulações linguísticas e a realidade externa, o material e o mental, etc. Surge daí um problema para a sociologia, que tradicionalmente se considera como não-ficção. As perguntas postas acima ao projeto de Law são cabíveis: ambos lançam sombras sobre a ética de pesquisa, por parecerem sugerir que as fronteiras entre o investigador e o objeto de pesquisa - fundo epistemológico das noções de método, premissas, resultados, etc. - precisam ser superadas. Ademais, quão legítima é uma crítica realizada a partir de um território conceitual particular, possivelmente incomensurável com o de seu objeto?

Partindo do desordenamento de distinções conceituais características do modernismo, Latour desenvolve uma forma peculiar de crítica à sociologia, que acompanha sua incursão teórica por um novo paradigma. Como sugerido acima, há uma radicalização e pós-modernização do construtivismo constitutivo, que é elevado a status de ontologia. A interpretação da literatura sociológica tradicional é feita por esse critério e é entendida como algo que não corresponde às novas exigências sociológicas e ao panorama de realidade que subsidia a teoria de Latour (2005, p.1, tradução nossa): 
Quando cientistas sociais adicionam o adjetivo "social" a algum fenômeno, eles designam um estado de coisas estabilizado, um monte de elos que, depois, podem ser mobilizados para dar conta de algum outro fenômeno. Não há nada errado com este uso da palavra na medida em que ela designa o que já está reunido, sem fazer qualquer suposição supérflua sobre a natureza do que é associado. Problemas surgem, contudo, quando "social" passa a significar um tipo de material [...]. Naquele ponto, o sentido da palavra se quebra já que agora ela designa duas coisas completamente diferentes: primeiro, um movimento durante um processo de associação; e segundo, um tipo de ingrediente específico que deveria diferir de outros materiais.

O que desejo fazer no presente trabalho é mostrar por que o social não pode ser construído como um tipo de material ou domínio e disputar o projeto de prover uma "explicação social" de outro estado de coisas.

Tendo em mente a epistemologia modernista sugerida no início do ensaio, as colocações de Latour são bastante questionáveis: suas motivações e críticas são movidas por um tom metafísico/ontológico, diferente do analítico/heurístico do póspositivismo. Suas afirmações sobre o que uma parte da sociologia faz ("tomar o social como algo estável") vão bem além da distinção entre conceito e termo, por tentarem capturar afirmações sobre realidades últimas que, na visão de Latour, acompanham algumas teorizações. A inabilidade modernista de afirmar algo sobre a natureza de conceitos como social dá lugar para infinitas afirmações vistas em todos os lugares, e neste terreno as propostas de Reassembling the Social são germinadas.

$\mathrm{Na}$ esteira de tais visões metafísicas segue a fundamentação de Latour para sua Teoria Ator-Rede (TAR). Partindo de sua visão de mundo — generativa e polissêmica - calcada no construtivismo constitutivo, ele postula que a sociologia tradicional não reflete bem tais características, e por isso precisa de um novo instrumental analítico. Como meio de justificar a incursão por uma nova teoria há o "princípio da completude" (também vista em Bourdieu e Law) - a motivação por um quadro fiel da realidade social, uma completude do conhecimento traçado em relação ao que ilustra, a tentativa de fazer da sociologia uma "ciência da realidade". Contudo, é necessário apontar que há momentos em que Latour de certa forma corrobora a epistemologia modernista ao lembrar a limitação das teorias frente a suas pretensões analíticas (ibidem, p.258-62, tradução nossa):

Isso não significa que tais disciplinas são ficções, inventando seus objetos da cabeça. Significa que elas são, como o nome agradavelmente indica, disciplinas: cada uma escolheu implantar um tipo de mediador e favoreceu um tipo de estabilização, então povoando o mundo com diferentes tipos de habitantes bem treinados e inteiramente formatados. [...]

Este livro é apenas uma introdução para ajudar o leitor interessado em tomar as consequências em teoria social da sociologia da ciência. Não estou apto a dizer se alguém acabará usando essas ferramentas em qualquer ofício.

Principia 18(3): 371-391 (2014). 
Contudo, como mostrado acima e exemplificado na forma empregada para descrever que diferentes áreas do conhecimento (disciplinas) têm objetos de pesquisa limitados, Latour está mais interessado em mostrar uma visão de mundo - e os novos termos que a acompanham - tornando os benefícios heurísticos da empreitada latourniana bastante controversos. Talvez isso possa ser sintetizado pelas perguntas: "há uma linguagem que consiga representar satisfatoriamente a potencialidade de significados construtíveis ao se olhar para a natureza?", "há linguagens que produzem uma afirmação tácita sobre essências cosmológicas?”. Os esforços de Latour acompanham profundas concepções enredadas em tais questões, no que foi elogiado como um grande empreendimento metafísico (Harman 2009).

Os conceitos de Latour (como "social") estão muito longe de serem termos. Não têm apenas uma funcionalidade, mas também são painéis de complexas visões de mundo. E como toda metafísica, essas visões são difíceis de serem apreendidas. Latour expõe apenas uma parte delas, que é seguida com perdas ou não pelos partidários de sua teoria ator-rede (TAR). Examinando o desenvolvimento dessa teoria na academia, surgem as perguntas: "o mundo externo é mais importante em sociologia do que a narrativa que é feita dele?", "tal narrativa deve estar envolvida por termos esotéricos para atender às necessidades da sociologia como disciplina?", "os conceitos são tão importantes quanto os termos?". A obra de Latour convida para um mundo particular, que tenta ditar as regras para todos os outros mundos pela força de suas unidades constitutivas — os conceitos.

Latour discorre sobre a etimologia da palavra "social" $(2005$, p.6) e chega a uma conclusão estranha: através do tempo, ela foi ganhando cada vez mais usos distintos, e isso quer dizer que o significado da palavra foi encolhendo! Uma pequena investigação sobre os usos comuns da palavra conduz a sérias dúvidas sobre sua proposta. Em relação ao conceito de social, seus argumentos parecem muito mais um problema filosófico possuído por uma minoria de sociólogos, do que grandes conturbações no meio sociológico: "Nós não temos mais certeza sobre o que 'nós' significa: parecemos estar atados por 'laços' que não se parecem com laços sociais regulares" (ibidem, p.6). E quem são essas pessoas incertas? Da mesma forma que John Law, Latour evoca questões teóricas (metafísicas) que supostamente estão povoando o clima intelectual sociológico para fundamentar suas incursões.

Talvez a melhor forma de se entender a proposta de Latour (extensível a Law) seja mesmo no plano metafísico, e ignorando problemas de âmbito empirista que podem vir à tona (ibidem p.7-8):

religião não precisa ser 'representada' por forças sociais porque em sua própria definição — na verdade, em seu próprio nome — ela liga junto entidades que não são parte da ordem social. Organizações não precisam ser inseridas em um 'quadro social mais amplo' já que elas próprias dão um significado bem prático para o que significa estar aninhado em um estado de coisas 'mais 
amplo' [...] E o mesmo é válido para todos os outros domínios.

Bem, se tratarmos de conceitos tais afirmações são bastante plausíveis. No entanto, ao investigar o mundo externo, podem surgir confusões do tipo: "somente há uma relação social aqui se eu disser que há", "esta organização está inserida em um quadro social mais amplo ou não", "as religiões não têm aspectos sociais, mas algo que sugira que tenham pode ser afirmado", etc. Tais confusões são profundos obstáculos se pensadas no âmbito da epistemologia modernista, e da síntese proposta entre empiria e razão, que legitima proposições sobre o mundo externo no âmbito do espectro cognitivo humano.

Sob tais lentes, a consideração latourniana sobre os reducionismos que atravessam a mentalidade ocidental hegemônica (Harman 2009, p.13) são, grosso modo, uma intuição subjetiva que pode ser o caso ou não. A razoabilidade de pegar essa intuição para fundamentar um amplo projeto de sociologia - anunciando a exaustão do "modelo tradicional" — é bastante contestável. Nessa empreitada o caráter "redutivo" da linguagem ${ }^{14}$ (Wittgenstein 1968) e o hábito mental de tentar encaixar a realidade em termos absolutos (Dawkins 1993) humana são marginalizados com o propósito de dar força ao programa da TAR. Isso porque são tratados como aspectos intelectuais contornáveis, herdados de uma tradição cultural que pode ser solapada. Contudo, a alternativa latourniana não parece em nenhum momento superar tais questões, conseguindo apenas novos termos para substituir antigos.

Muito provavelmente Latour diria que a racionalidade que projetou minhas críticas é incompatível com a própria cosmologia que dita as regras de sua teoria, ou algo do gênero. As problemáticas acima acerca da TAR são novamente erguidas, e assim serão sempre para diversos leitores de Latour, os inconformados com o mundo particular por ele imaginado, com seu funcionamento generativo e os mil platôs de potencialidades. Se os conceitos das publicações de Latour são interessantes para a investigação sociológica, depende de cada um, ${ }^{15}$ e das vivências que consonaram ou não essas perspectivas com um âmbito semântico que vai muito além da mera utilização de termos.

Em Galis e Lee (2014), há um diálogo com a TAR, e a autorrefência como pós-TAR ( $\operatorname{sim}$, existe isso). Mas, assim como na pesquisa de Law citada acima, a cosmologia teórica de Latour parece dispensável para uma compreensão das ideias do texto, e os termos utilizados dispensam profundas digressões conceituais para serem apreendidos. Contudo, os autores intencionaram "fortalecer o vocabulário TAR tradicional em uma tentativa de neutralizar a reificação teórica e a coação de categorias teóricas rígidas" (ibidem, p.172, tradução nossa), com a mesma verve crítica de Bourdieu e Latour direcionada a esses "inimigos fantasmas". Esse esforço de uma parte da sociologia contemporânea tem uma verdadeira neura filosófica contra alguns sistemas de conhecimento, que estará sempre presente uma vez que a sociologia também é um 
esforço intelectual-linguístico que está sempre suscetível a tais acusações. Os impactos práticos dessas críticas são curiosos - Bourdieu não refutou Lévi-Strauss, nem Law e Latour o fizeram com o edifício intelectual passado - pois o que há de fato é a criação de novos "discursos do método" para serem adicionados à já extensa coleção da sociologia, em uma disputa de charmes intelectuais para absorver novos sociólogos em suas fileiras. Parece-me que a constante criação de novos vocabulários não provém totalmente de uma carência analítica dos termos anteriores, mas de uma constante preocupação em dissociar as proposições sociológicas de possíveis interpretações subjacentes que podem existir no leitor mais leigo, sem uma edificação intelectual básica que entenda as "regras do jogo", aqui sintetizadas como epistemologia modernista. ${ }^{16}$ Penso que esse empreendimento é louvável quando almeja evitar ambiguidades e fortalecer a clareza (enfocando no uso terminológico), mas nos níveis de Latour e Law, talvez o limite tenha sido ultrapassado, e as pretensões não passem de hologramas: projeções que possuem forma e estimulam os sentidos, mas que são carentes de substância.

\section{Conclusão}

Ao se ter em mente a perspectiva de conhecimento moderna aqui sugerida, tem-se que críticas como a de Bourdieu para Lévi-Strauss têm como pano de fundo um desenvolvimento das expectativas geradas em torno da produção sociológica, e o que ela deveria produzir. A sociologia - enquanto conceito - é tão plural que incursões críticas como essas são vistas como legítimas. De fato, um dos eixos do debate sociológico contemporâneo gira em torno dessa pluralidade, e dos efeitos que isso tem nos pesquisadores - objetivos distintos, que levam a uma grande variedade de métodos, que podem até ser incomensuráveis em face aos objetivos subjacentes impulsionando assim a confecção de diversos quadros analíticos feitos por autores diversos, dúzias de "discursos do método" selecionados pelos estudantes como "pais intelectuais". A necessidade terminológica para consultar o acervo do mundo externo é casualmente misturada com a "essência da análise sociológica", como consequência da confusão entre conceitos e termos.

A grande diversidade de programas de sociologia, isto é, expectativas criadas sobre os objetivos da pesquisa sociológica, acarretam a convivência acadêmica de metodologias e visões de mundo com epistemologias incomensuráveis. A lente modernista aqui projetada é uma entre várias, que pode enxergar um vazio quando analisa teorias como as de Latour e Law. Tais autores concedem muito mais liberdade às palavras, no sentido de permitirem que elas se movimentem de formas para muitos irrazoáveis. O estilo da prosa é muito importante nessa vertente — "pós-moderna" - em detrimento daquilo a que elas buscam se referir, como no caso da epígrafe do

Principia 18(3): 371-391 (2014). 
ensaio. ${ }^{17} \mathrm{Na}$ verdade, a função referencial da linguagem não é uma regra nesses esquemas intelectuais. O que é regra não está bem claro. O que está claro é o carisma dessas teorias nos sociólogos atuais. Mas mesmo assim ainda há a divisão: de um lado, há os "antiquados" que seguem a epistemologia modernista, o pós-positivismo, ou simplesmente a razão. De outro, há os "pluriversalistas" que constroem teorias baseadas em mundos bem diferentes daquele em questão para os primeiros - o "mundo real". 18

\section{Referências}

Bhambra, G. 2007. Rethinking modernity: postcolonialism and the sociological imagination. Nova York: Palgrave Macmillan.

Bourdieu, P. 1989. O Poder Simbólico. Rio de Janeiro: Bertrand Brasil.

—. 2003. Esboço de uma teoria da prática. In: R. Ortiz (org.), A sociologia de Pierre Bourdieu. São Paulo: Olhos D’Água, p.47-81.

- 2011. Razões Práticas: Sobre a teoria da ação. Campinas: Papirus Editora.

Bourdieu, P; Passeron, J-C. 2008. A Reprodução: Elementos para uma teoria do sistema de ensino. Petrópolis: Vozes.

Calhoun, C. et al. 2012. The Sociological Theory of Pierre Bourdieu. In: C. Calhoun, Contemporary Sociological Theory. West Sussex: Wiley-Blackwell, p.325-34.

Connell, R. 2007. Southern theory: The global dynamic of knowledge in social sciences. Cambridge: Polity.

Czarniawska, B. 2006. Book Review: Bruno Latour: Reassembling the Social: An introduction to actor-network theory. Organization Studies 27: 1553-57.

Davidson, D. 1973-1974. On the Very Idea of a Conceptual Scheme. Proceedings and Addresses of the American Philosophical Association 47: 5-20.

Dawkins, R. 2014. Conheça meu primo, o chimpanzé. Disponível em: http://str.com.br/Scientia/chimpanze.htm Acesso em: 29 jan 2014.

Durkheim, É. 1978. As regras do método sociológico. São Paulo: Ed. Nacional.

Galis, V.; Lee, F. 2014. A sociology of treason: The construction of weakness. Science, Technology \& Human Values 39: 154-79.

Garfinkel, H. 1967. Studies in ethnometodology. Englewood Cliffs: Prentice-Hall.

Gerrans, P. 2005. Tacit knowledge, rule following and Pierre Bourdieu's philosophy of social science. Anthropological Theory 5: 53-74.

Gusmão, L. 2012. O Fetichismo do Conceito: Limites do Conhecimento Teórico na Investigação Social. Rio de Janeiro: Topbooks.

Haddock, G. 2013. Some Heterodox Analytic Philosophy. Principia 17(2): 235-49.

Harman, G. 2009. Prince of Networks: Bruno Latour and Metaphysics. Melbourne: re.press. Jain, S. 2013. Bourdieu's sociology: A post-positivist science. Thesis Eleven 117: 101-16.

James, W. 1979a. Pragmatismo. In: Os pensadores (William James). São Paulo: Abril Cultura, p.1-109.

- 1979b. Ensaios em empirismo radical. In: Os pensadores (William James). São Paulo: Abril Cultura, p.171-230.

Principia 18(3): 371-391 (2014). 
Kant, I. 1980. Crítica da razão pura. In: Os pensadores (Kant I). São Paulo: Abril Cultural.

Latour, B. 1994. Jamais Fomos Modernos: Ensaio de Antropologia Simétrica. Rio de Janeiro: Editora 34.

- 2005. Reassembling the Social. Cambridge: Cambridge University Press.

- 2012. We Have never Been Modern. In: C. Calhoun (ed.). Contemporary Sociological Theory. West Sussex: Wiley-Blackwell, p.546-59.

Latour, B.; Woolgar, S. 1997. A Vida de Laboratório: a produção dos fatos científicos. Rio de Janeiro: Relume Dumará.

Law, J. 2004. After Method: mess in social science research. New York: Routledge.

Luhmann, N. 2013. Introduction to Systems Theory. Cambridge: Polity Press.

Pears, D. 1973. As Idéias de Wittgenstein. São Paulo: Cultrix.

Quine, W.V.O. 1951. Two Dogmas of Empiricism. The Philosophical Review 60: 20-43.

Ruppert, E.; Law, J.; Savage, M. 2013. Reassembling social science methods: The challenge of digital devices. Theory, Culture \& Society 30(4): 22-46.

Sokal, A. 1996a. A physicist experiments with cultural studies. Lingua Franca, Mai.

. 1996b. Transgressing the Boundaries: Towards a Transformative Hermeneutics of Quantum Gravity. Social Text 46/47: 217-52.

Swartz, D. 1997. Culture \& Power: The sociology of Pierre Bourdieu. Chicago: UChicago Press. Vandenberghe, F. 2006. Construção e crítica na nova sociologia francesa. Sociedade e Estado 21(2): 315-66.

Whittle, A.; Spicer, A. 2008. Is Actor Network Theory critique? Organization Studies 29: 61129.

Wittgenstein, L. 1968. Tractatus Logico-Philosophicus. São Paulo: Cia. Nacional.

\author{
BRUNO NOGUEIRA \\ bruno.laze@gmail.com
}

Resumo. A proposta do ensaio é ilustrar segmentos de debates contemporâneos em sociologia, no que concerne questões epistemológicas. Uma dicotomia termo x conceito será fomentada para dar vazão às ideias, relacionando um autor já consagrado - Pierre Bourdieu — com dois nomes mais recentes - John Law e Bruno Latour - que apresentaram novas teorias de longo alcance, constitutivas de uma sociologia bastante heterodoxa. Na fonte dessa dicotomia está uma epistemologia modernista, que será grosseiramente (re)elaborada antes dos outros temas serem aprofundados. Será argumentado que a não observação de alguns detalhes epistemológicos acompanha algumas críticas presentes nos debates, bem como os próprios debates, e também é combustível para alimentar a plausibilidade das teorias sociológicas dos autores analisados.

Palavras-chave: Epistemologia da crítica; relativismo crítico; kantianismo; modernismo.

\title{
Notas
}

${ }^{1}$ http://www.elsewhere.org/pomo/ Acesso em: 30 jan 2014 Tradução nossa. Gostaria de agradecer aos pareceristas pela sugestões que resultaram no melhoramento do escopo e estrutura do artigo.

Principia 18(3): 371-391 (2014). 
${ }^{2}$ Isso não quer dizer que essa racionalidade moderna tem a "autoridade" para conferir certeza sobre o que é conhecimento ou não, pois questões dessa natureza são comunitariamente/subjetivamente resolvidas, e quando são (em outras palavras, a correspondência entre proposição e fato é metafísica). Dentro desse paradigma, postula-se a existência de termos, e não conceitos, no sentido de que todo uso de palavras estará restrito a uma significação específica. Há, por exemplo, estudos sobre o conhecimento tácito ou prático (Gerrans, 2005), mas que não refutam o uso anterior da palavra, associado ao simbólico (como em Kant, 1980), se entendermos que o que está em questão são termos, ou seja, têm significação reduzida a contextos de uso particulares. O mesmo vale para o uso da palavra "moderno" nesse ensaio, que se refere aqui à tradição de pensamento mais casual na Academia, mas que pode ter outros significados em outros momentos.

${ }^{3} \mathrm{O}$ que não quer dizer que os investigadores da totalidade e da potência do significado, nomeadamente idealistas, não sejam contemporâneos. Estão bastante presentes, por exemplo, em filosofia, sociologia e antropologia. Bruno Latour foi elogiado por um filósofo por sua metafísica (Harman, 2009).

${ }^{4}$ Como colocado por William James: "Para os pensadores que chamo neokantianos, [...] a experiência é indestrutivelmente dualista em sua estrutura. Significa que não só o sujeito, nem só o objeto, mas o objeto-mais-o-sujeito é o mínimo que pode realmente ser." (1979b, p.174). A tentativa de superar essa dualidade no empirismo radical, me parece, ironicamente, não ter consequências práticas para o caso aqui proposto. Em outras palavras, o sujeito metafísico não anula o sujeito heurístico; ou então, pode haver agente sem alma.

${ }^{5}$ A metafísica kantiana tenta chegar ao limite dessa circunscrição, buscando enunciar as faculdades do entendimento que condicionam a possibilidade de conhecimento. Meu ponto neo-kantiano é direcionar essas limitações humanas a sociais e culturais, no sentido de que culturas muito distintas podem ter choques cognitivos incomensuráveis. Essas colocações são bem sintetizadas no aforisma "Os limites de minha linguagem denotam os limites de meu mundo." (Wittgenstein 1968, p.111, grifo no original).

${ }^{6}$ Isso significa que em última instância não há como comparar seleções, para decidir qual seria a mais válida, a não ser dentro dos próprios limites socioculturais em que a seleção ocorre.

${ }^{7}$ Sob esses argumentos, a condenação bourdieusiana se volta para recentes teorias sociológicas como a de Latour (2005) e Law (2004), que buscam ampliar os horizontes do que estaria permitido aos sociólogos em seu trabalho. Podemos entender tais esforços como uma "luta de abstrações reificadas", com cada participante querendo implantar uma nova visão na arena. O moderno aforisma bourdieusiano "um ponto de vista é a visão de um ponto" parece ser ignorado para dar lugar à "maximização teórica" de um ponto de vista particular. Apesar de não haver impedimentos lógicos ou filosóficos para a expressão de tais opiniões, muitas de suas críticas expressas a outros sociólogos são descabidas, pela impossibilidade lógica e filosófica de se hierarquizar apreensões particulares de conceitos.

${ }^{8}$ Outros exemplos notáveis desse tipo de crítica estão na escola pós-colonialista, no ato de usar dados empíricos sobre a vida dos autores como fundamento (Bhambra 2007) ou alegorias supostamente deslegitimadoras (Connell 2007). Elas também não se limitam ao âmbito analítico-heurístico, para criticar em face ao que lhes apetece como exercício sociológico.

${ }^{9} \mathrm{http}: / /$ heterogeneities.net/papers.htm Acesso em: 09 mai 2014.

${ }^{10}$ Outro argumento controverso: seria a literatura acadêmica em grande parte chata de ler?

Principia 18(3): 371-391 (2014). 
Law sugere (2004, p.11-12) que romances são em geral bem escritos e prazerosos de serem lidos, e que textos acadêmicos não absorvem a habilidade textual de romancistas. A afirmação é razoável, senão pelos argumentos seguintes: pela elegância, é razoável minimizar questões de clareza ou veracidade.

${ }^{11}$ Não busco minimizar com isso que certas interpretações estão mais presentes do que outras — talvez esta seja a dimensão política do conhecimento - mas que filosoficamente não há como compará-las se não há regras consensuais para a comunicação e argumentação, como no caso Sokal.

12 Por leigo e não leigo me refiro ao grau de condicionamento para se expressar nos termos criados por Latour. No caso das dificuldades dos não leigos, são mais passíveis de acontecer em discussões com pessoas orientadas pelas distinções conceituais da epistemologia modernista. Também é importante lembrar que o uso dos termos em questão por Latour está no plano do longo alcance teórico: "modernistas, híbridos, Grande Divisão" — não se esclarece o contexto particular de inserção de tais termos — daí a semelhança com a metafísica (Harman 2009).

${ }^{13}$ Latour dessa forma reverte o princípio neokantiano de troca da ontologia pela epistemologia. Isso fica claro em sua pretensão de resgatar dos "pré-modernos" a não separação de coisas e signos, e dos "pós-modernos" o construtivismo (1994).

${ }^{14}$ Isso quer dizer que a linguagem "seleciona" assuntos (objetos) deixando outros possíveis de lado para o momento. Nesse sentido pode-se dizer que "reduz a coisa".

${ }^{15}$ Partidários da teoria crítica, por exemplo, não acham TAR compatível com suas intenções (Whittle; Spicer 2008).

16 O exemplo já mencionado da física, em que interpretações dos termos "energia" e "matéria" da teoria da relatividade levaram aos conceitos de mesmo nome, que por sua vez fundamentaram discursos de autoajuda, esoterismo, etc. ilustra a possibilidade de má interpretação ou uma associação oportunista.

${ }^{17}$ No entanto, ela não é totalmente absurda, pois está tendo um uso retórico nesse texto. Esse é um argumento bastante usado pelos pós-modernos para se defenderem de críticas modernas a algumas de suas passagens, alegadamente linguagem sem nexo: há um sentido externo à compreensão textual tradicional, que os modernos não entendem ou não toleram. Programas de computador produzindo ensaios sociológicos podem ser evidência de uma nova era pós-moderna.

18 Talvez seja mais adequado tratar essa unidade epistemológica modernista não como uma afirmação ontológica sobre a constituição da realidade, já que isso também não passaria de especulação metafísica, mas de forma holística intralinguística. As regras para as proposições são dessa forma validadas em sua relação com o resto das proposições que compõem o sistema (que implanta suas próprias regras operativas), sendo minimizado o problema da verificação (sistemas são incomensuráveis por se definirem por operações particulares). Cf. Quine 1951; Luhman 2013.

Principia 18(3): 371-391 (2014). 